\title{
Increase of Zinc Finger Protein 179 in Response to CCAA T/Enhancer Binding Protein Delta Conferring an Antiapoptotic Effect in Astrocytes of Alzheimer's Disease
}

\author{
Shao-Ming Wang • Yi-Chao Lee $\cdot$ Chiung-Yuan Ko $•$ Ming-Derg Lai $\cdot$ Ding-Yen Lin • \\ Ping-Chieh Pao • Jhih-Ying Chi • Yu-Wei Hsiao • Tsung-Lin Liu • Ju-Ming Wang
}

Received: 8 February 2014 / Accepted: 10 April 2014 /Published online: 1 May 2014

(C) The Author(s) 2014. This article is published with open access at Springerlink.com

\begin{abstract}
Reactive astrogliosis is a cellular manifestation of neuroinflammation and occurs in response to all forms and severities of the central nervous system (CNS)'s injury and disease. Both astroglial proliferation and antiapoptotic processes are aspects of astrogliosis. However, the underlying mechanism of this response remains poorly understood. In addition, little is known about why activated astrocytes are more resistant to stress and inflammation. CCAAT/enhancer binding protein delta (CEBPD) is a transcription factor found in activated astrocytes that surround $\beta$-amyloid plaques. In this study, we found that astrocytes activation was attenuated in the cortex and hippocampus of APPswe/PS1 E9 (AppTg)/ $\mathrm{Cebpd}^{-1}$ mice. Furthermore, an increase in apoptotic astrocytes was observed in $\mathrm{AppTg} / \mathrm{Cebp}^{{ }^{-}}$mice, suggesting that CEBPD plays a functional role in enhancing the antiapoptotic
\end{abstract}

Yi-Chao Lee and Chiung-Yuan Ko contributed equally to this study.

Electronic supplementary material The online version of this article (doi:10.1007/s12035-014-8714-9) contains supplementary material, which is available to authorized users.

S.-M. Wang $\cdot$ M.-D. Lai $\cdot$ J.-Y. Chi

Institute of Basic Medical Sciences, College of Medicine, National

Cheng Kung University, Tainan 701, Taiwan

D.-Y. Lin $\cdot$ P.-C. Pao $・$ Y.-W. Hsiao $・$ T.-L. Liu $\cdot$ J.-M. Wang $(\bowtie)$ Institute of Bioinformatics and Biosignal Transduction, College of Bioscience and Biotechnology, National Cheng Kung University,

Tainan 701, Taiwan

e-mail:wwwjm4721@yahoo.com.tw

J.-M. Wang

Infectious Disease and Signaling Research Center, National Cheng

Kung University, Tainan 701, Taiwan

D.-Y. Lin $\cdot$ J.-M. Wang

Center of Molecular Inflammation, National Cheng Kung University,

Tainan 701, Taiwan ability of astrocytes. We found that Zinc Finger Protein 179 (ZNF179) was a CEBPD-regulated gene that played an antiapoptotic, but not proliferative, role in astrocytes. The transcriptions of the proapoptotic genes, insulinlike growth factor binding protein 3 (IGFBP3) and BCL2-interacting killer (BIK), were suppressed by ZNF179 via its interaction with the promyelocytic leukemia zinc finger (PLZF) protein in astrocytes. This study provides the first evidence that ZNF179, PLZF, IGFBP3, and BIK contributed to the novel CEBPDinduced antiapoptotic feature of astrocytes.

Keywords Alzheimer's disease - CEBPD - ZNF179 · Astrocytes · Antiapoptosis

J.-M. Wang

Graduate Institute of Medical Sciences, Taipei Medical University, Taipei 110, Taiwan

Y.-C. Lee • C.-Y. Ko

Ph.D. Program for Neural Regenerative Medicine, College of Medical Science and Technology, Taipei Medical University, Taipei 110, Taiwan

Y.-C. Lee • C.-Y. Ko

Center for Neurotrauma and Neuroregeneration, Taipei Medical University, Taipei 110, Taiwan 


\section{Introduction}

Aging is accompanied by a low-grade chronic neuroinflammation and aged rat neurons show signs of programmed cell death $[1,2]$. Astrocyte is the most abundant cell type of glial cells and suggests being involved in the induction of neuroinflammation. Previous studies reported no change in the number of astrocytes in the hippocampus of male aged mice [2] and activated astrocytes are more resistant to death signals in highly inflammatory environments [3, 4]. Interestingly, the number of astrocytes increases by approximately $20 \%$ in aging brains [5], suggesting that reactive gliosis responds to injured or damaged neurons during aging. The above discoveries indicated that the antiapoptosis of aged astrocytes contributes to the death of neurons. However, the underlying mechanisms have not been investigated. Alzheimer's disease $(\mathrm{AD})$ is pathologically characterized by the age-dependent deposition of $\beta$-amyloid $(A \beta)$ in senile plaques and is associated with neuroinflammation. $A \beta$ can activate astrocytes, thus promoting inflammatory cytokines production, which is believed to modulate the development and/or progression of $\mathrm{AD}$. Astrogliosis (also known as astrocytosis or reactive astrocytes) is characterized by the proliferation and hypertrophy of astrocytes, and is usually observed in neurodegenerative disorders and central nervous system (CNS) injuries [6].

CCAAT/enhancer binding protein delta (CEBPD) is a member of the CCAAT/enhancer binding protein (C/EBP) family and has been shown to be activated in many inflammatory diseases, including $\mathrm{AD}[7,8]$ and rheumatoid arthritis [9]. CEBPD is responsive to tumor necrosis factor alpha (TNF $\alpha$ ), interleukin-1 beta (IL-1 $\beta$ ), interleukin 6 (IL-6), lipopolysaccharide, and interferon gamma $[8,10]$. In astrocytes, CEBPD activation attenuates macrophage-mediated phagocytosis of damaged neurons and promotes chemoattraction and migration of microglia/macrophages through PTX3 and MCP1 , respectively $[8,11]$. However, the function of CEBPD in astrocytes and neuroinflammation-related diseases, especially its potential role in astrogliosis, remains largely uninvestigated.

Zinc finger protein 179 (ZNF179 or RNF112) belongs to the RING finger protein family, which is characterized by a zinc binding domain that serves as a potent protein binding interface. Mouse ZNF179 (Znf179) is specifically expressed in the mouse brain $[12,13]$. Znf179 is expressed exclusively in the mouse brain and the expression is high in MAP2positive cells and moderate in glial fibrillary acidic protein (GFAP)-positive cells in normal subjects [14]. However, the ZNF179 biology in brain remains largely unclear. A recent study showed that $\mathrm{Znf179}$ regulates cell cycle exit, which is critical for neuronal differentiation and plays a potent role in cell survival [12].

Herein, we found that the loss of GFAP signal associated with the increase of caspase 3 signal was observed in App Tg/
$\mathrm{Cebpd}^{{ }^{--}}$mice. Focusing on the survival (or resistance to stress-induced apoptosis) of astrocytes in inflammatory environment, we first showed that CEBPD played a functional role in inducing the resistance of cell death in an inflammatory environment. ZNF179 is attenuated following the IL- $1 \beta$ stimulation in neuronal cells. We further found that ZNF179 is responsive to CEBPD induction in astrocytes and contributes the CEBPD-induced antiapoptosis. Two pro-apoptotic genes insulin-like growth factor binding protein 3 (IGFBP3) and BCL2-interacting killer (BIK) were identified by a system approach and were negatively regulated by the complex of ZNF179 and promyelocytic leukemia zinc finger (PLZF). These discoveries provide a new insight into the resistance of astrocytes to inflammation and the control of astrogliosis.

\section{Materials and Methods}

\section{Materials}

The CEBPD and green fluorescent protein (GFP) antibodies were purchased from Santa Cruz Biotechnology (Santa Cruz, CA, USA). The GFAP antibody was purchased from Invitrogen (Carlsbad, CA, USA). The caspase 3 antibody was purchased from Cell Signaling Technology (Danvers, MA, USA). The ZNF179 antibody used for immunofluorescence was purchased from GeneTex (Irvine, CA, USA), and the ZNF179 antibody used in the Western blot and immunoprecipitation assays was obtained from Dr. Yi-Chao Lee. The TRIzol RNA extraction reagent, Dulbecco's modified Eagle's medium (DMEM), and SuperScript ${ }^{\mathrm{TM}}$ III were purchased from Invitrogen (Carlsbad, CA, USA). All oligonucleotides were synthesized by MDBio Inc. (Taipei, Taiwan). Fetal bovine serum (FBS) was purchased from HyClone Laboratories (Logan, UT, USA).

\section{Animals}

The APPswe/PS1/E9 bigenic (AppTg) mice were obtained from the Jackson Laboratory (stock no. 004462, Bar Harbor, ME, USA). The AppTg mice were crossed with Cebpd-deficient mice $\left(\mathrm{Cebp}^{\prime-}\right)$, a kind gift from Dr. E. Sterneck [15], on the C57BL/6 genetic background. Female mice heterozygous for AppTg mice was intercrossed with $C e b p d^{1-}$ homozygous mice; the offspring $\left(A p p \mathrm{Tg}^{+/-} / C e b p d^{+/-}\right)$were then bred to each other to produce the $\mathrm{App} \mathrm{Tg} / \mathrm{Cebpd}^{{ }^{--}}$mice in this study.

\section{Cell Culture and Isolation of Primary Mouse Astrocytes}

Human U373MG cells, an established cell line derived from human astrocytoma and HeLa cells (human cervical 
epithelioid carcinoma cell line), were cultured in DMEM. SHSY5Y cells (human neuroblastoma cell line) were maintained in DMEM/F12. All media contained $10 \%$ FBS, $100 \mu \mathrm{g} / \mathrm{mL}$ streptomycin, and 100 units/ml penicillin. U373MG cell lines stably expressing hemagglutinin (HA), HA-ZNF179, or HACEBPD were selected and maintained by regular media containing G418. The primary mouse brain astrocytes were isolated from $\mathrm{Cebpd}^{+/+}$or Cebpd $d^{/-}$mice using mechanical dissociation of the brain cortex from newborn pups. The isolated cells were then filtered through a $70-\mu \mathrm{m}$ nylon strainer and cultured in the previously described medium [16] with the addition of poly-L-lysine (Invitrogen, Carlsbad, CA, USA).

Cell Survival, Proliferation, and Fluorescence-Activated Cell Sorting Analysis

For the cell survival assay, cells were plated and cultured in the aforementioned regular medium for $16 \mathrm{~h}$. The experimental cells were then treated with or without $100 \mu \mathrm{g} / \mathrm{mL}$ methanesulfonate (MMS; Sigma, St. Louis, MO, USA) or $5 \mathrm{ng} / \mathrm{mL}$ IL- $1 \beta$ (Invitrogen, Carlsbad, CA, USA). Next, the media was removed and replaced with diluted 3-(4,5-cimethylthiazol-2-yl)-2,5diphenyl tetrazolium bromide (MTT) reagent for $4 \mathrm{~h}$. The samples were then measured spectrophotometrically at $595 \mathrm{~nm}$ using an ELISA plate reader. For cell proliferation assay, daily cell culture samples were counted in a Neubauer chamber after trypsinization. Viability was assessed by Trypan blue exclusion. Assays were performed in triplicates. For the apoptosis assay, cells were plated and cultured in the aforementioned regular medium for $16 \mathrm{~h}$. The experimental cells were then treated with or without MMS or IL-1 $\beta$ for $24 \mathrm{~h}$. As indicated times or experimental conditions, the cells were fixed in cold $70 \%$ ethanol at $-20{ }^{\circ} \mathrm{C}$ overnight and then suspended in phosphatebuffered saline (PBS) containing $0.2 \%$ Triton X-100, $0.1 \mathrm{mg} / \mathrm{ml}$ RNase and $40 \mu \mathrm{g} / \mathrm{mL}$ propidium iodide at room temperature for $1 \mathrm{~h}$. The apoptosis of experimental cells was analyzed using flow cytometry (FACSCalibur; BD Biosciences, Mountain View, CA).

\section{Reverse Transcription-PCR and Quantitative PCR}

Total RNA was extracted using the TRIsure RNA extraction reagent. The synthesis of complementary DNA (cDNA) was completed with an reverse transcription (RT) reaction using SuperScript III. Quantitative PCR (Q-PCR) was conducted using KAPA SYBR FAST qPCR Master Mix (Life Technologies Corporation and Kapa Biosystems Inc.). PCR was conducted using a CFX connect real-time PCR system (Bio-Rad) with the following pairs of specific primers: primer sequences human CEBPD (S): 5-'GCCATGTACGACGACG AGAG-3' and CEBPD (AS): 5-'TGTGATTGCTGTTGAA GAGGTC-3'; mouse Cebpd (S): 5-'CTCCCGCACACAAC ATACTG -3' and Cebpd (AS): 5-'AGTCATGCTTTCCCGT
GTTC-3', ZNF179 (S): 5-'GAGCAGGGAAACAAGGAT CA-3' and ZNF179 (AS): 5-'GGTGGGATGAGTCACGAT CA-3', RYBP (S): 5-'TGACATTGCAGTGGTGGTTT-3' and RYBP (AS): 5-'CCATGTCAGGACTGGATGTG-3', BIK (S): 5-'CCTGGACCCTATGGAGGACT-3' and BIK (AS): 5-'GGTGAAACCGTCCATGAAAC-3', GADD45B (S): 5-' ACCTGCATTGTCTCCTGGTC-3' and GADD45B (AS): 5-' TTTGTTTGTGGCAGCAACTC-3', IGFBP3 (S): 5-'AGGG CACTCTGGGAACCTAT-3' and IGFBP3 (AS): 5-'TGCA GTCATCCGAAGAATTG'.

\section{Western Blot Analysis}

Cells were harvested and lysed with modified radioimmunoprecipitation assay (RIPA) buffer $[50 \mathrm{mM}$ Tris-HCl (pH 7.4), $150 \mathrm{mM}$ sodium chloride, $1 \mathrm{mM}$ ethylenediamine tetraacetic acid, $1 \%$ NP40, $0.25 \%$ sodium deoxycholate, $1 \mathrm{mM}$ dithiothreitol, $10 \mathrm{mM} \mathrm{NaF}$, $1 \mathrm{mM}$ PMSF, $1 \mu \mathrm{g} / \mathrm{mL}$ aprotinin, and $1 \mu \mathrm{g} / \mathrm{mL}$ leupeptin]. Lysates were resolved on a sodium dodecyl sulfatecontaining $10 \%$ polyacrylamide gel, then transferred to a polyvinylidene difluoride nylon membrane and probed with primary antibodies for target proteins at $4{ }^{\circ} \mathrm{C}$ overnight. The specific proteins were detected by peroxidaseconjugated secondary antibody incubated at room temperature for $1 \mathrm{~h}$. The signals were revealed by an enhanced chemiluminescence Western blot system from Pierce (Rockford, IL, USA).

\section{Luciferase Reporter Assay}

The $5^{\prime}$ flanking regions of ZNF179, IGFBP3 and BIK genes were obtained by PCR with U373MG genomic DNA and then individually cloned into a pGL3 basic vector. The primers for the PCR of the genomic DNA were: ZNF179 (S): 5'-KpnI-GGGG TACCCCGCGCCAAGCCTATCACATATCC-3', ZNF179 (AS): 5'-HindIII-CCCAAGCTTGGGCTGCGGTAGGTAGA AGGTGAGG-3'; IGFBP3(S): 5'-MluI-CGACGCGTCGAG TGCTACACTAACCAGTGGTC-3', IGFBP3 (AS): 5'HindIII-CCCAAGCTTGGGAATCCAGGCAGGAAGCGG CTGATC-3', BIK(S):5'-NheI-CTAGCTAGCTAGCTCTTCCT CCTTTTGATCAGC-3', and BIK (AS):5'-BgIII-GAAGATCT TCTAAAACCTGGGCACGGCTC-3'. For the reporter assay, cells were transfected with the reporters and expression vectors as indicted using polyJet (SignaGen, Ijamsville, MD). The lysates of transfected cells were harvested following the manufacturer's instructions for the luciferase assay.

Co-Immunoprecipitation Assay

The lysates of U373MG cells were prepared using an immunoprecipitation lysis buffer $[50 \mathrm{mM} \mathrm{NaCl}, 0.5 \% \mathrm{NP}-40$, 
$10 \mathrm{mM}$ Tris- $\mathrm{HCl}$, (pH 8.0)]. The supernatant was collected and incubated with anti-GFP antibody at $4{ }^{\circ} \mathrm{C}$ for at least $4 \mathrm{~h}$. Protein-A/G agarose beads were added to the lysates and the mixtures were incubated and rotated at $4{ }^{\circ} \mathrm{C}$ for $1 \mathrm{~h}$. The beads were collected using centrifugation and washed three times with modified RIPA buffer. The proteins bound to the beads were eluted by adding $2 \mathrm{X}$ electrophoresis sample buffer and then subjected to Western blot analysis.

\section{Lentiviral Short Hairpin RNA Knockdown}

The virus was produced from Phoenix cells using a cotransfection of the various short hairpin RNA (shRNA) expression vectors in combination with pMD2.G and psPAX2 expression vectors. The expression vectors were obtained from the National RNAi Core Facility located at the Genomic Research Center of Institute of Molecular Biology, Academia Sinica, Taiwan. After determining the viral infection efficiency, the lentivirus containing $\operatorname{sh} \beta$-galactosidase (shLacZ), shCEBPD, or shZNF179 were used to infect U373MG cells for $48 \mathrm{~h}$. The shRNA sequences in the lentiviral expression vectors were shLacZ, 5'-CCGGTGTT CGCATTATCCGAACCATCTCGAGATGGTTCGGATAA TGCGAACATTTTTG-3', shCEBPD, 5'-CCGGGCCGAC CTCTTCAACAGCAATCTCGAGATTGCTGTTGAAGAG GTCGGCTTTTT-3' and shZNF179, 5'-CCGGCTTCATGG ACTCCTACACGATCTCGAGATCGTGTAGGAGTCCAT GAAGTTTTTG-3'.

\section{Chromatin Immunoprecipitation Assay}

Briefly, U373MG cells were treated with $1 \%$ formaldehyde for $15 \mathrm{~min}$. The cross-linked chromatin was then prepared and sonicated to an average size of $500 \mathrm{bp}$. The DNA fragments were immunoprecipitated with specific antibodies recognizing CEBPD, ZNF179, PLZF, or control rabbit immunoglobulin $\mathrm{G}(\mathrm{IgG})$ at $4{ }^{\circ} \mathrm{C}$ for $12-16 \mathrm{~h}$. After reversal of the crosslinking between proteins and genomic DNA, the precipitated DNA was amplified by PCR with primers related to the specific regions on the genomic loci of target genes. The primers included ZNF179-I forward, 5'-GGGCTCTGTACA TAGTAGGTACTC-3' and ZNF179-I reverse, 5'-GCCTCT ACTGGGCCAGCTGAGGTC-3' or ZNF179-II forward, 5'CTTGGTGCACCCATCTTTGCATC-3' and ZNF179-II reverse, 5'-AGGCATTGCTATGATCTGGGTGAG-3'. IGFBP3 forward, 5'-CACGTGAGAGTCTTCTTGCGTT GAG-3' and IGFBP3 reverse, 5'-ATACAGCGCTCCGCAT TCGTGTG-3', or BIK forward, 5'-CCCCTGGCTTCGGG TATGGATCAC-3' and BIK reverse, 5'-TATCGGGGGGAT CGATCCATTGAC-3'.
Immunofluorescence Analysis

The frozen male mouse brain sections ( 15-16 months of age) were treated with protein blocker/antibody diluents (Bio SB, Santa Barbara, CA, USA) for $1 \mathrm{~h}$. In the same buffer solution, the sections were incubated overnight with primary antibodies at $4{ }^{\circ} \mathrm{C}$. These primary antibodies included cleaved caspase 3 , GFAP, A $\beta$, Znf179, and CEBPD. Statistical analysis of immunofluorescent staining intensity in cortex or hippocampus of brain slices from AppTg or AppTg/Cebpd ${ }^{-/}$mice was done using TissueQuest 4.0 image software. For the staining of cell cultures, U373MG cells were post-fixed in $4 \%$ paraformaldehyde in PBS for 20 min, followed by $70 \%$ methanol in PBS at $-20{ }^{\circ} \mathrm{C}$ for $10 \mathrm{~min}$. The fixed U373MG cells were further incubated with primary antibodies against target proteins in $3 \%$ BSA at $4{ }^{\circ} \mathrm{C}$. Pretreated slides of the tissue sections or U373MG cells were washed with $0.2 \%$ Triton X-100 in PBS and then incubated with Alexa 488- or 555-conjugated secondary antibodies for $1 \mathrm{~h}$ at room temperature then washed again with $0.2 \%$ Triton X-100 in PBS. Next, the glass slides were counter-stained and mounted with ProLong Gold antifade reagent with 4',6-diamidino-2-phenylindole for immunofluorescence microscopy.

\section{Statistical Analysis}

All experiments were repeated at least three times, and data were analyzed for statistical significance by two-tailed unpaired Student's $t$ test using Prism 5 software. The data were expressed as means \pm SEM. Differences were considered statistically significant when indicated by asterisks.

\section{Results}

Astrocyte Activation is Attenuated in the Area Surrounding $\beta$-Amyloid Plaques in AppTg/Cebpd ${ }^{--}$Mice

Activated astrocytes are largely resistant to cell death in a neuroinflammatory environment. In $\mathrm{AD}$ patients and $\mathrm{App} \mathrm{Tg}$ mice, the expression of CEBPD and mouse CEBPD (Cebpd), respectively, is elevated and localized within astrocytes [7, 8] (Fig. S1A). The immunoreactivity for GFAP, a specific astrocyte marker, was attenuated in both the cortex and hippocampus of $\mathrm{AppTg} / \mathrm{Cebpd}^{--}$mice when compared with $\mathrm{AppTg}$ mice (Fig. 1a, b). To assess whether apoptosis contributes to the reduction of astrocytes in $\mathrm{AppTg} / \mathrm{Cebpd}^{--}$mice, activated caspase 3 , an apoptosis marker, was used to measure the death of astrocytes in brain sections from App Tg and $A p p \mathrm{Tg} /$ Cebpd $^{/-}$mice. As shown in Fig. 1c, d, activated caspase 3 was upregulated and colocalized with the GFAP-positive astrocytes in AppTg/Cebpd ${ }^{-1}$ mice. This suggests that CEBPD contributes to the survival of astrocytes in AppTg mice. 
$\mathbf{a}$
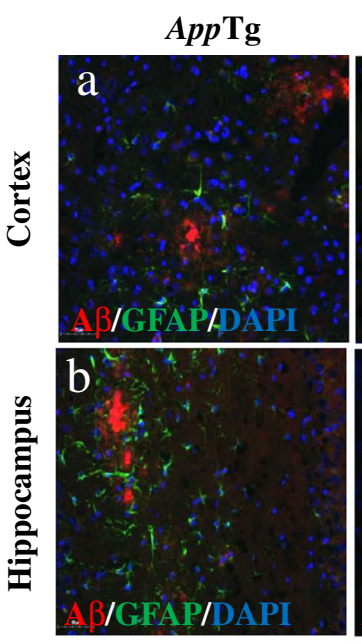

C
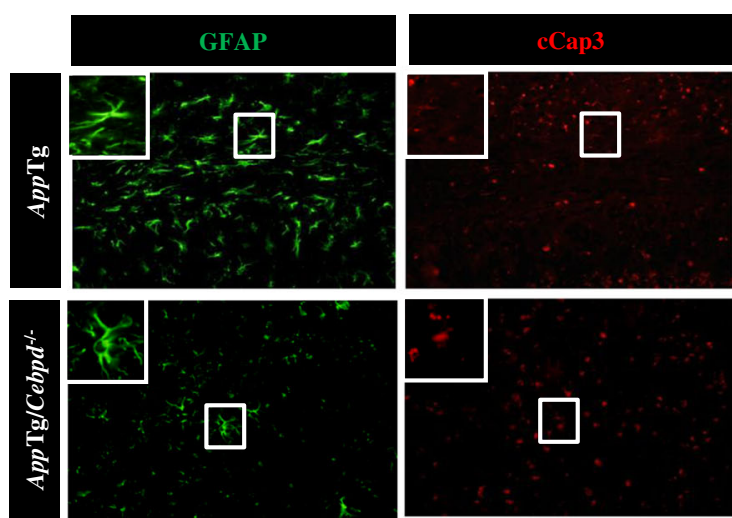

Fig. 1 Astrocyte activation was decreased in $\mathrm{AppTg} / \mathrm{Cebpd}^{/-}$mice. a Astrocyte numbers were decreased in the area surrounding $\beta$-amyloid plaques in $\mathrm{AppTg} / \mathrm{Cebpd}^{-/}$mice. The brain tissue was subjected to immunofluorescence with anti-GFAP and anti- $\beta$-amyloid. b Quantitative analysis of GFAP staining in cortex and hippocampus brain sections of $A p p \mathrm{Tg}$ and $A p p \mathrm{Tg} / \mathrm{Cebpd}^{-1-}$ mice using TissueQuest software. c Loss of

\section{CEBPD Plays an Antiapoptotic Role in Astrocytes}

Several reports have suggested that astrocytes are more resistant to death in an inflammatory environment when compared to neurons $[3,17,18]$. CEBPD is known to be activated in astrocytes in response to IL- $1 \beta$ and TNF $\alpha[8,11]$. We first tested whether the activated CEBPD contributes to the antiapoptosis of astrocytes. After $24 \mathrm{~h}$ of IL- $1 \beta$ treatment, CEBPD indeed responded to IL- $1 \beta$ stimulation and the level of apoptosis in U373MG and primary mouse astrocytes was not significantly different from that before treatment (Fig. 2a, b). In contrast to astrocytes, we found decreased CEBPD in and increased death of neuronal SH-SY5Y cells after $24 \mathrm{~h}$ of IL-1 $\beta$ treatment (Fig. S1B). To assess if CEBPD plays an antiapoptotic role in astrocytes, we generated d
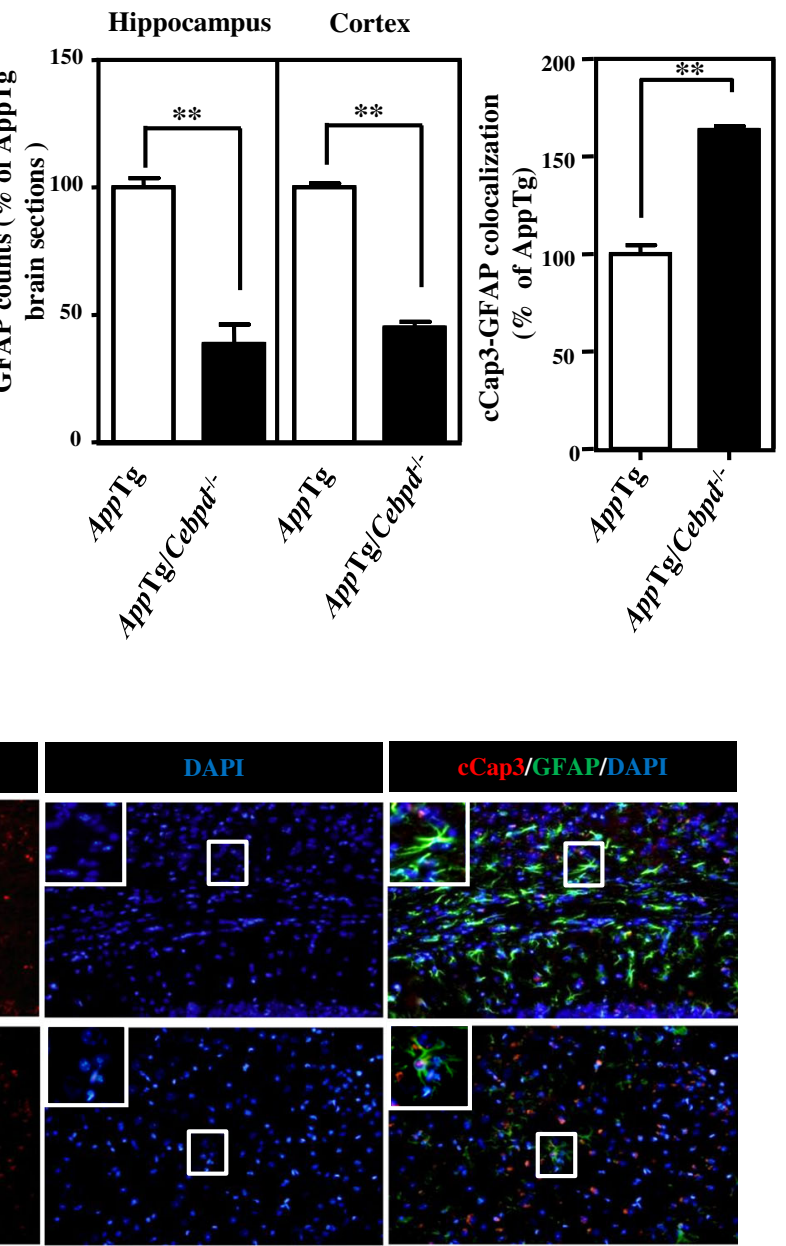

CEBPD promotes astrocyte death in $A p p \mathrm{Tg} / \mathrm{Cebpd}^{-/}$mice. The brain tissue was subjected to immunofluorescence with anti-GFAP and anticleaved caspase-3 (cCap3). d Quantitative analysis of GFAP and cCap3 immunofluorescent signal in whole brain sections of $A p p \mathrm{Tg}$ and $A p p \mathrm{Tg}$ Cebpd $^{/-}$mice using TissueQuest software. ( ${ }^{* *} p<0.01$, Student's $t$ test). cCap3 cleaved caspase-3; GFAP glial fibrillary acidic protein

U373MG cells that stably expressed CEBPD. As shown in Fig. 2c, the overexpression of CEBPD in U373MG cells increased survival and reduced apoptosis after exposure to MMS, a strong apoptosis inducer. Importantly, in Cebpd $d^{+/+}$ and $\mathrm{Cebpd}^{/-}$primary astrocytes, the cells lacking CEBPD showed increased cell death after IL-1 $\beta$ treatment (Fig. 2d). These data suggest that increased CEBPD in astrocytes has a functional role in antiapoptosis

\section{ZNF179 Gene is a Direct Target of CEBPD}

We found that the expression of ZNF179 was responsive to IL-1 $\beta$ treatment in astrocytes (Fig. 3a). Furthermore, the expression of ZNF179 paralleled that of CEBPD in astrocytes (Fig. S1C). We next sought to determine the relationship 
$\mathbf{a}$

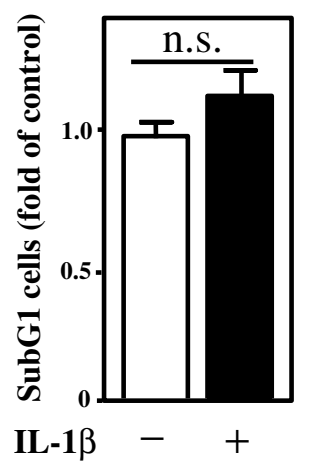

c

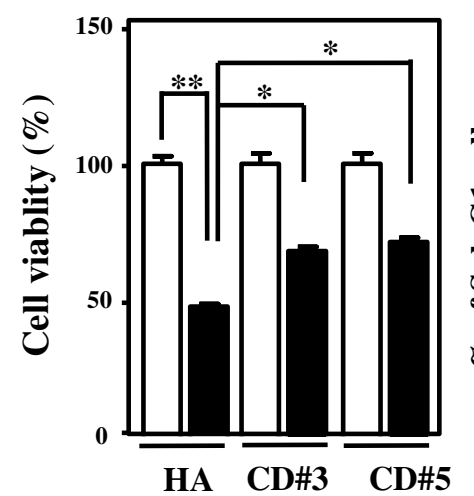

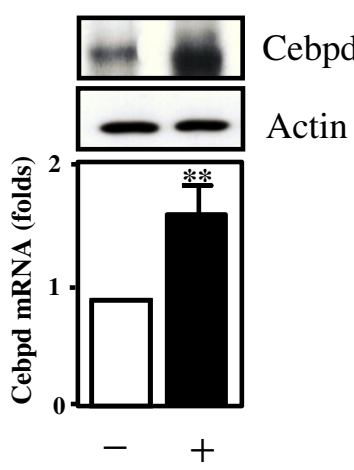

b

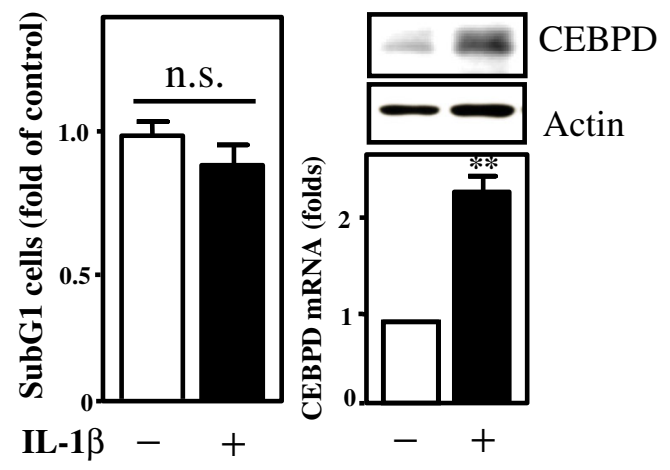

\section{HA CD\#3 CD\#5}

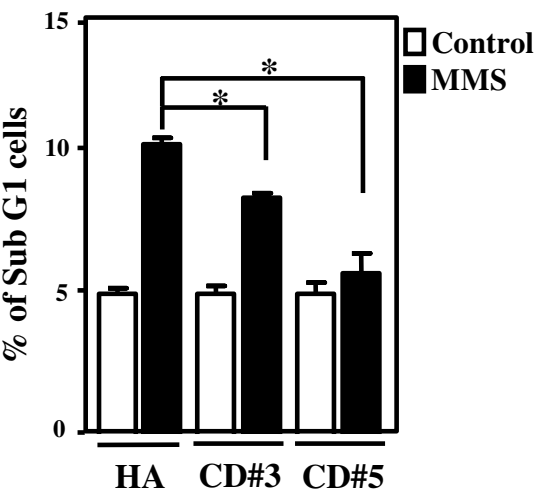

d

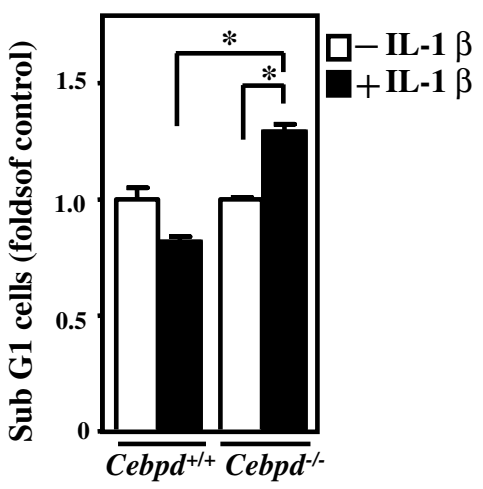

Fig. 2 CEBPD promotes astrocyte survival and activation after exposure to inflammatory cytokines. a Primary mouse astrocyte and b U373MG cells are resistant to IL-1 $\beta$-induced cell death. The dead cells were stained with PI and were localized to the sub-G1 population using flow cytometry. RT-PCR and Western blot analyses were conducted with specific primers and the indicated antibodies using total RNA and protein lysates harvested from IL-1 $\beta$-treated cells. c CEBPD protects U373MG cells against MMS-induced death. The MTT assay and PI staining were conducted as indicated. d Loss of CEBPD in primary astrocyte cultures increased cell death after IL- $1 \beta$ treatment. The PI staining was conducted as indicated. $\left({ }^{*} p<0.05,{ }^{* *} p<0.01\right.$, Student's $t$ test). CD CEBPD; $n . s$. not significant between ZNF179 and CEBPD. A reporter assay showed that Cebpd could activate a Znf179 promoter-driven reporter, but the expressed $\mathrm{Znf179}$ had no effect on a Cebpd promoterdriven reporter (Fig. S2). These data suggest that CEBPD is an upstream regulator of the ZNF179 gene in astrocytes. Moreover, the effect of IL-1 $\beta$-induced Znf179 transcription was attenuated in primary astrocyte cultures derived from $\mathrm{Cebpd}^{-1-}$ mice (Fig. 3b). A similar result was found for CEBPD-related ZNF179 transcription and expression in U373MG cells (Fig. 3c). Using a serial deletion reporter assay, we identified a potent CEBPD responsive region in the ZNF179 promoter at $-282 /+72$ bp (Fig. 3d). In addition, an in vivo DNA binding assay showed that the binding of CEBPD on the ZNF179 promoter was responsive to IL-1 $\beta$ in U373MG cells (Fig. 3e). These data suggest that CEBPD regulates
ZNF179 transcription by directly binding to the ZNF179 promoter region.

\section{ZNF179 Expression in Astrocytes Contributes} to Antiapoptosis

Although a previous study suggested that ZNF179 might contribute to the survival of neurons [12], the effect of ZNF179 in astrocytes is unknown. ZNF179 has been suggested to be a brain-specific gene [12, 19]. An immunofluorescence assay showed that ZNF179 was detectable in the GFAP-positive astrocytes of AppTg mice and was attenuated in the astrocytes of $\mathrm{AppTg} / \mathrm{Cebpd}^{-1-}$ mice (Fig. 4a). To determine if ZNF179 plays an antiapoptotic role, we established the stable expression of ZNF179 in human cervical HeLa cells. After MMS or TNF $\alpha$ exposure, HeLa cells with 
a

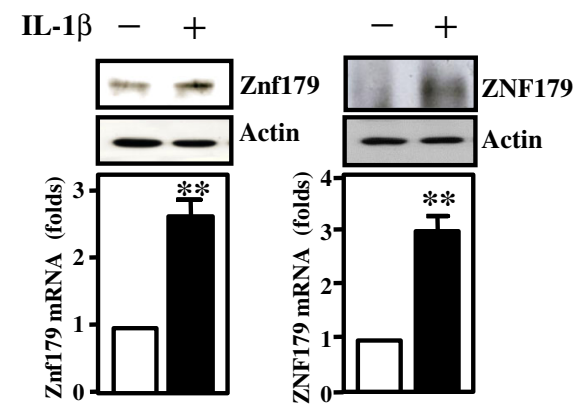

b

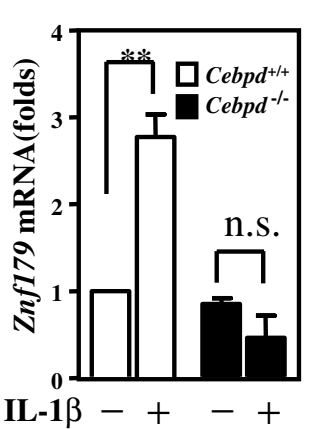

c

pMT/

d

Reporters

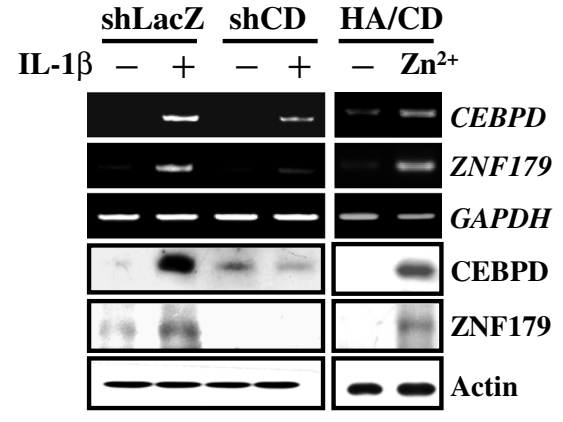

d

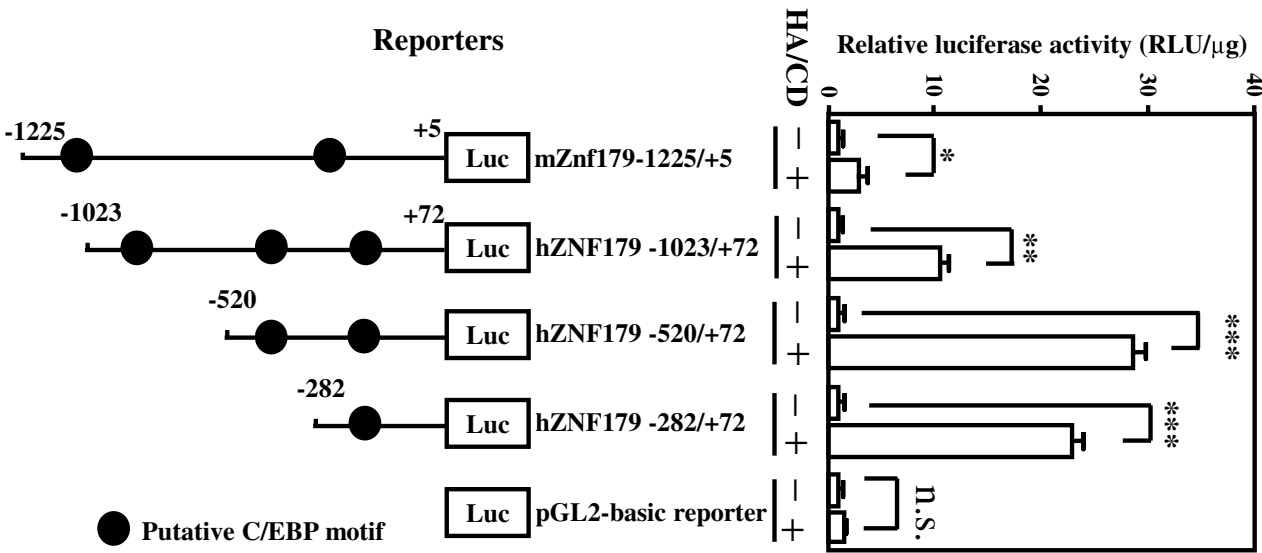

e
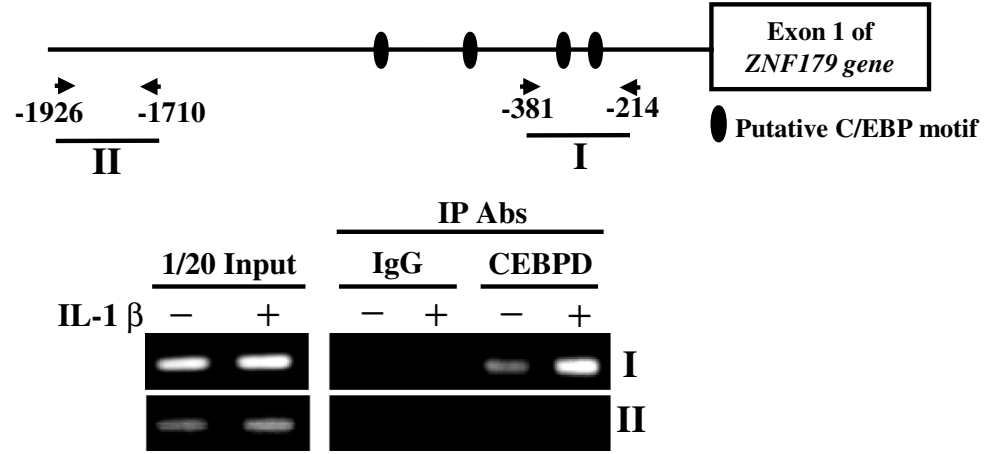

IP Abs

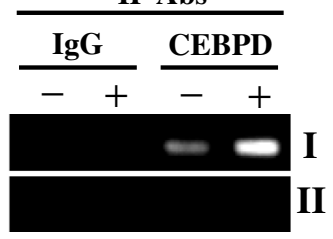

Fig. 3 CEBPD directly regulates ZNF179 transcription in U373MG cells. a Primary mouse astrocytes (left panel) and U373MG cells (right panel) were responsive to IL-1 $\beta$ treatment. RT-PCR and Western blot analyses were conducted with specific primers and the indicated antibodies using total RNA and protein lysates harvested from IL- $1 \beta$-treated cells. b The lack of Cebpd did not induce Znf179 expression in primary astrocyte cultures. A Q-PCR assay was performed using total RNA harvested from $\mathrm{Cebpd}^{+/+}$and $\mathrm{Cebpd}^{-1-}$ primary astrocytes. c CEBPD participates in IL-1 $\beta$-induced ZNF179 transcription. RT-PCR and Western blots were performed with total RNA and protein lysates harvested from stable U373MG cells with pMT-CEBPD expression vector (right

panel) or IL-1 $\beta$-treated U373MG cells with or without attenuation of CEBPD (left panel). $\mathbf{d}$ The identification of CEBPD responsive motifs on the ZNF179 promoter region. The representation of reporter constructs (upper panel). A reporter assay was conducted using the luciferase activity of the ZNF179 reporter/CEBPD expression vector co-transfected cell lysates. e CEBPD directly binds to the ZNF179 promoter in vivo. A chromatin immunoprecipitation assay was performed with the immunoprecipitation products at the indicated Abs from U373MG cells treated with IL-1 $\beta$. $\left({ }^{*} p<0.05,{ }^{* *} p<0.01,{ }^{* * *} p<0.001\right.$, Student's $t$ test). $s h C D$ short hairpin CEBPD; $H A / C D$ HA-tagged CEBPD; n.s. not significant; $I P$ immunoprecipitation; $A b s$ antibodies

ZNF179 showed a resistance to MMS- or TNF $\alpha$-induced apoptosis (Fig. S3A and S3B). A similar result was observed in U373MG cells stably expressing ZNF179 (Fig. 4b, c). A gain-of-function approach was used to assess if the lack of ZNF179 or CEBPD impacts the IL-1 $\beta$-induced apoptosis of astrocytes. U373MG cells with reduced ZNF179 showed a loss of CEBPD and increased apoptosis after IL- $1 \beta$ exposure (Fig. 4d). Furthermore, the attenuation of ZNF179 decreased the CEBPD-related antiapoptotic effect after MMS exposure (Fig. 4e). These results suggest that ZNF179 is expressed in the astrocytes of $A p p T g$ mice, and it contributes to astrocytic CEBPD-dependent antiapoptotic effects. 
Fig. 4 ZNF179 attenuates the IL-1 $\beta$ /MMS-induced death of U373MG cells. a Znf179 is highly expressed in the astrocytes of $A p p \mathrm{Tg}$ mice when compared with $\mathrm{App} \mathrm{Tg} / \mathrm{Cebpd}^{-/}$mice. Sagittal sections of brain cortex were prepared from $A p p T$ Tg and App Tg/Cebpd ${ }^{-1}$ mice and then subjected to immunofluorescence with anti-GFAP, and anti-Znf179 antibodies. b and $\mathbf{c}$ ZNF179 protects U373MG cells against MMS-induced death. The MTT assay and PI staining were conducted as indicated. $\mathbf{d}$ Loss of CEBPD or ZNF179 increased cell death after IL- $1 \beta$ treatment. The PI staining was conducted as indicated. e The knockdown of ZNF179 in CEBPD overexpressing cells increased cell death after MMS treatment. The PI staining was conducted as indicated $\left({ }^{*} p<0.05, * * p<0.01\right.$, $* * * p<0.001$, Student's $t$ test). HZ HA-tagged ZNF179; shCD short hairpin CEBPD; $s h Z N$ short hairpin ZNF179; GFAP glial fibrillary acidic protein; $H A / C D$ HA-tagged CEBPD; shLacZ, $\operatorname{sh} \beta$-galactosidase a

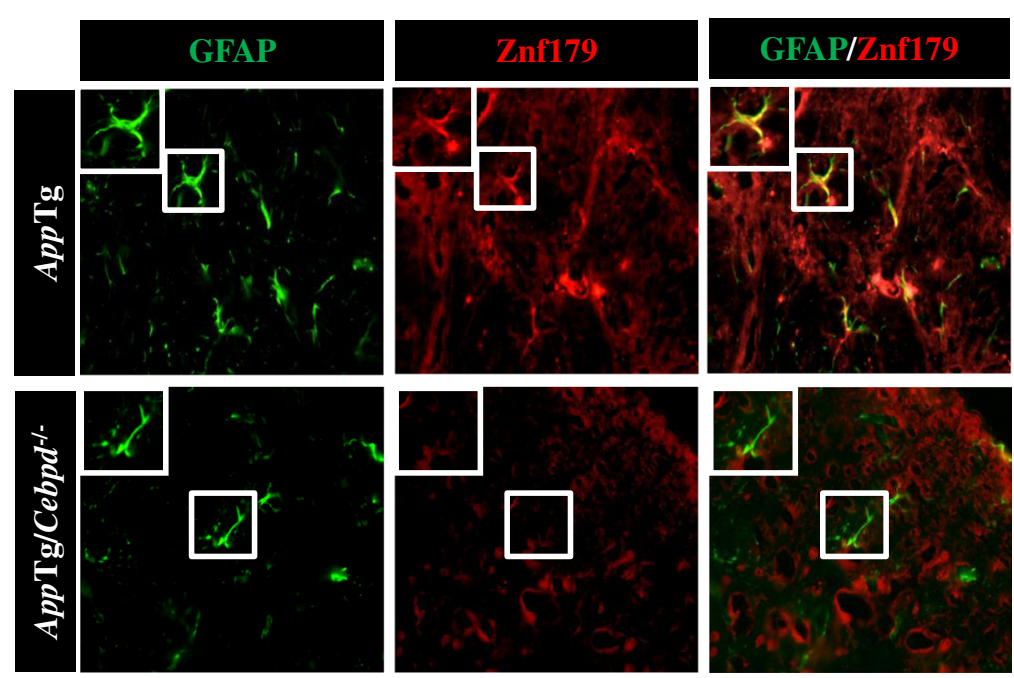

b
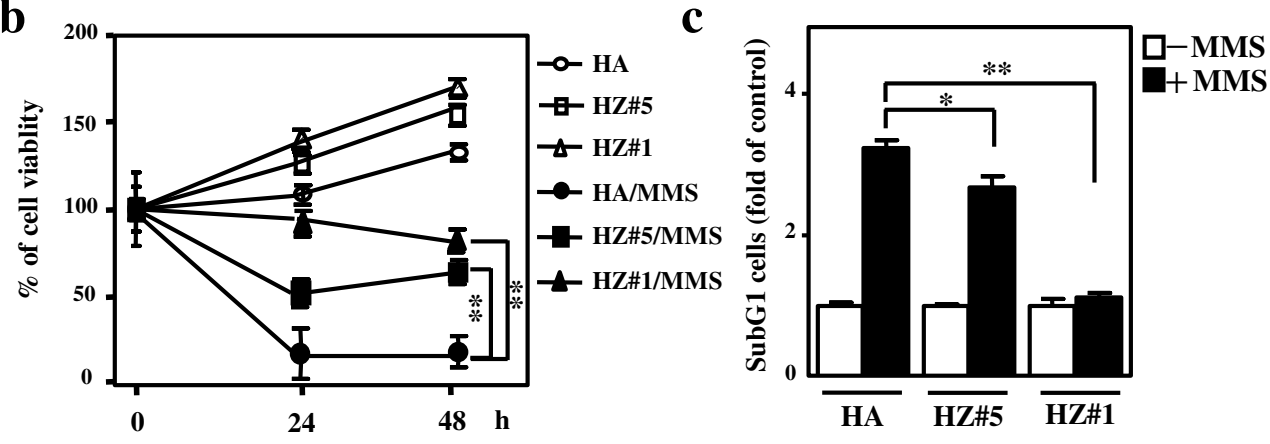

d

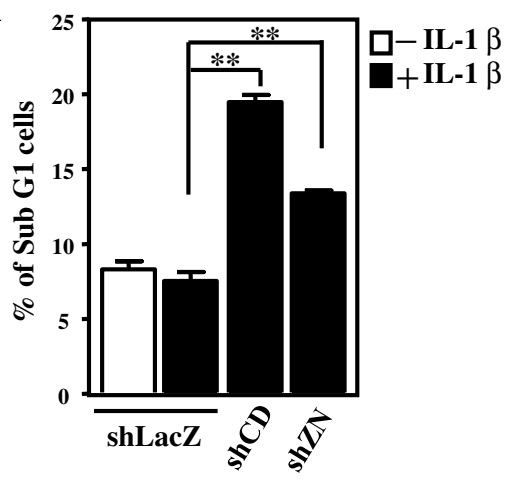

e

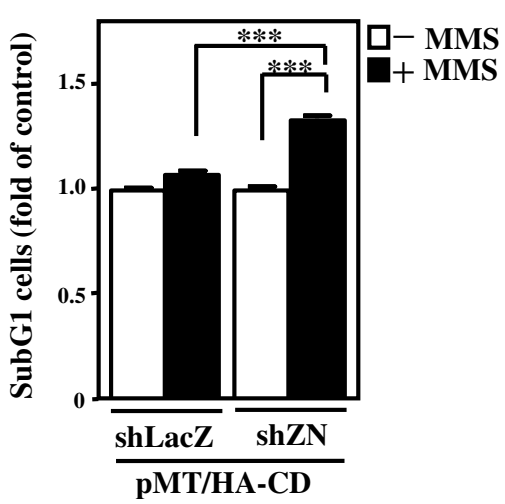

The Identification of ZNF179-Regulated Genes in U373MG Cells

We demonstrated that ZNF179 plays a functional role in antiapoptosis. However, the ZNF179-responsive genes related to the antiapoptotic processes in astrocytes remain unknown. Genome-wide profiling and comparisons were conducted using U373MG cells with and without the stable expression of HA/ZNF179. As shown in Fig. 5a, we found that a total of 98 genes were significantly induced by ZNF179 and 339 genes were inhibited by ZNF179 in U373MG cells. Among these ZNF179-responsive genes, four proapoptotic genes, including $R Y B P$ [20], BIK [21], GADD45B [22] and IGFBP3 [23, 24], were downregulated by ZNF179. RT-PCR and Q-PCR assays confirmed the findings from the microarray profile (Fig. $5 b)$.

ZNF179 Inhibits IGFBP3 and BIK Expression by Interacting with PLZF in Astrocytes

We next sought to determine if these ZNF179-regulated genes were also responsive to IL- $1 \beta$. By Q-PCR analysis, we found 
Fig. 5 The identification of ZNF179-regulated genes in astrocytes. a A microarray analysis was performed using total RNA harvested from stable U373MG cells with a pcDNAHA-ZNF179 expression vector. b The verification of CEBPD responsive genes in antiapoptosis. RT-PCR and Q-PCR assays were conducted using total RNA harvested from $\mathrm{HA}$ and $\mathrm{HZ}$ U373MG cells. $\left({ }^{*} p<0.05\right.$, $* * p<0.01$, Student's $t$ test). HZ HA-tagged ZNF179 $\mathbf{a}$
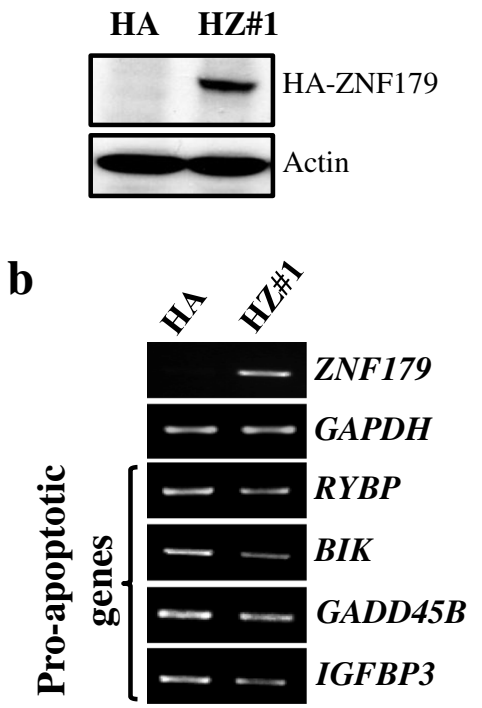
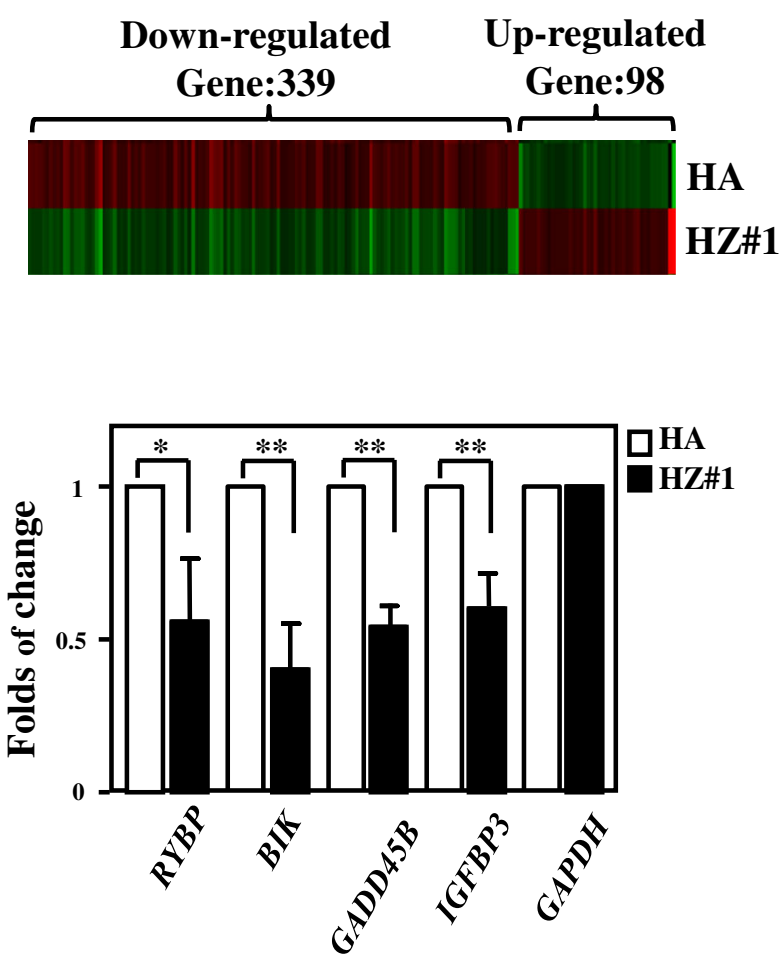

that only the IGFBP3 and $B I K$ transcripts out of the four ZNF179-responsive proapoptotic genes were downregulated in IL-1 $\beta$-treated astrocytes (Fig. 6a). PLZF protein belongs to the family of Krüppel-like zinc finger proteins. Our recent study showed that ZNF179 can interact with PLZF in neurons [25]. Here, a Co-immunoprecipitation assay showed that ZNF179 also interacted with PLZF in astrocytes (Fig. 6b). Focusing on IGFBP3 and BIK, a serial deletion of IGFBP3 and $B I K$ promoters were cloned into a pGL3 basic vector. We identified two putative PLZF binding motifs at $-535 /-543$ and $-452 /-460$ of the IGFBP3 promoter region and three motifs at $-498 /-488,-425 /-416$, and $-376 /-368$ of the $B I K$ promoter region (Fig. 6c, upper panel). Using a reporter assay, we found that overexpression of PLZF repressed the activities of $I G F B P 3$ and $B I K$ reporters containing potent PLZF binding sites. The co-transfection of PLZF and ZNF179 expression vectors showed an extensive effect on the repression of $I G F B P 3$ and $B I K$ reporter activity (Fig. $6 \mathrm{c}$, bottom panel). Furthermore, the loss of ZNF179 reduced the PLZF-mediated repression of IGFBP3 and $B I K$ reporter activity after IL- $1 \beta$ exposure (Fig. 6d). To verify if the IGFBP3 and BIK genes were directly regulated via the binding of PLZF and ZNF179, lysates of IL-1 $\beta$-treated U373MG cells were subjected to a chromatin immunoprecipitation assay. Our results show that the binding of PLZF and ZNF179 to the IGFBP3 and BIK promoter was responsive to IL-1 $\beta$ in U373MG cells (Fig. 6e). These data suggest that PLZF is an important component of IL-1 $\beta$-induced ZNF179-mediated suppression of IGFBP3 and $B I K$ transcription.

\section{Discussion}

In addition to $\mathrm{AD}$, neuroinflammation has been suggested to play a critical role in the pathogenesis of several neurodegenerative disorders, including Parkinson's disease and Huntington's disease [26]. Activation of astrocytes and microglia has been associated with the pathogenesis of $\mathrm{AD}$. However, the precise mechanisms involved in this process remain largely unclear. CEBPD is critical for the activation of astrocytes, but not for the microglia and neurons that surround $\mathrm{A} \beta$ plaques in $\mathrm{AD}$ (Fig. S1A) [7, 8, 11]. Under oxidative stress or inflammation, activated astrocytes were more resistant to apoptosis when compared with neurons (Fig. S1A and 2A) [3]. Our previous study showed that a significant reduction in astrocytes was observed in $A p p T g /$ Cebpd $^{-/}$mice [11]. In this study, we demonstrated that the loss of Cebpd promoted the death of GFAP-positive cells in the cortex and hippocampus of $A p p T g$ mice partly through the induction of apoptosis (Fig. 1c). Moreover, we demonstrated that the increase of CEBPD in astrocytes reduced MMS- or IL-1 $\beta$-induced apoptosis (Fig. 2). These data suggest that CEBPD plays an antiapoptotic role in astrocytes, especially in a stress environment.

Elevated CEBPD expression has been mainly found in the astrocytes of $\mathrm{AD}$ patients and $A p p \operatorname{Tg}$ mice $[7,8,11]$. We determined that the activation of CEBPD in astrocytes results in attenuation of macrophage-mediated phagocytosis of damaged neurons, and also contributes to microglial activation and migration $[8,11]$. In response to damaged or inflammatory 
a

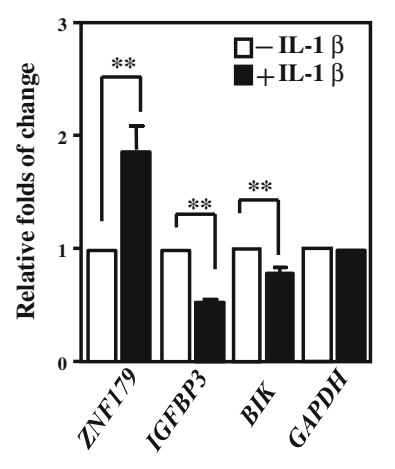

c
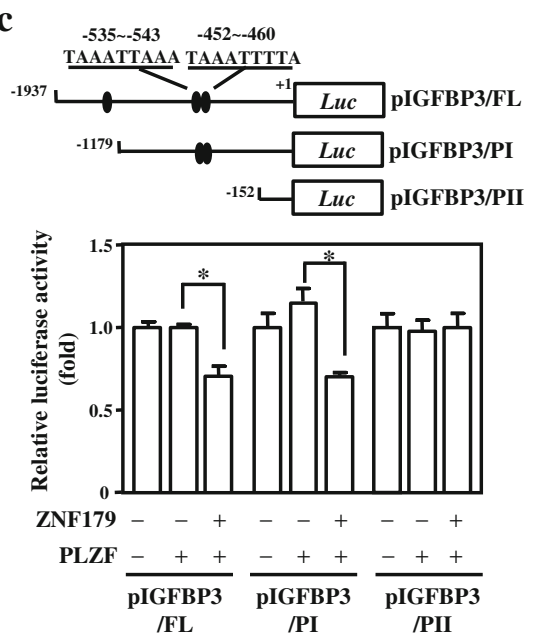

d

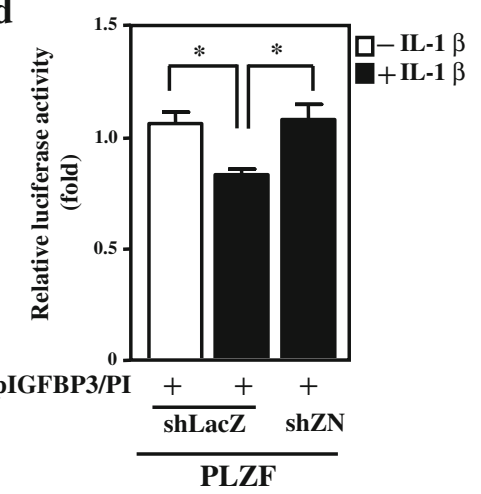

e

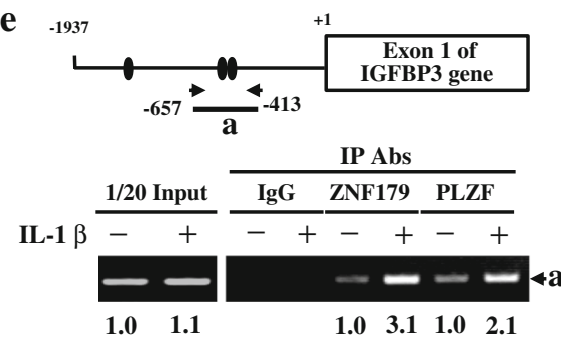

b
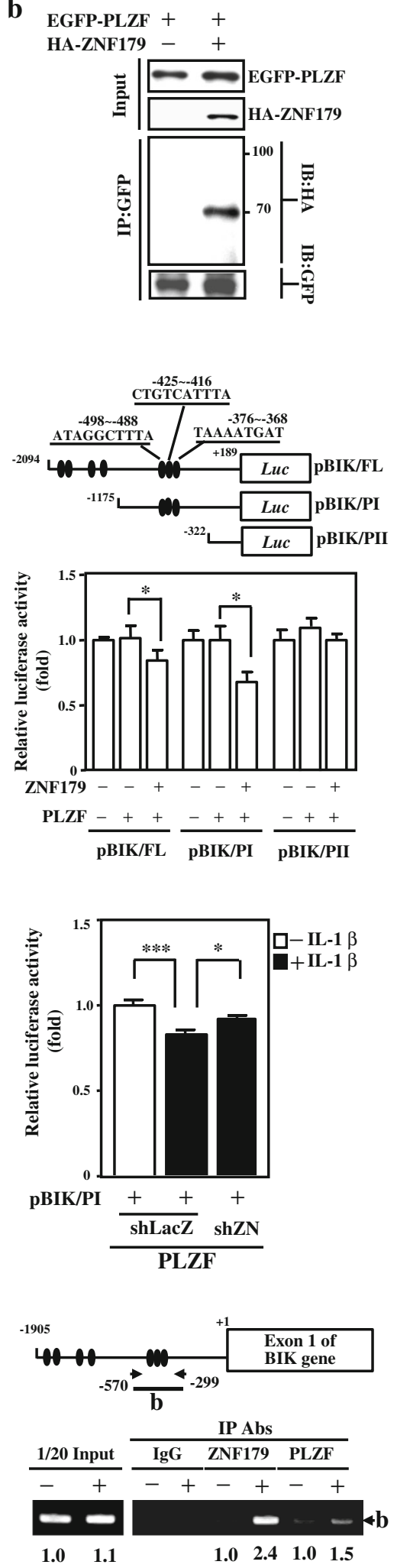

environments, neurons are more sensitive than astrocytes because they have lower antioxidant capabilities and are therefore prone to excitotoxicity [27]. Our novel findings suggest that astrocytic CEBPD plays an antiapoptotic role, which contributes to the resistance of inflammation-induced apoptosis in the inflamed brain. Meanwhile, we also showed 
4 Fig. 6 ZNF179 downregulates IGFBP3 and BIK expression through interaction with PLZF. a IGFBP3 and BIK expression was downregulated after IL-1 $\beta$ treatment. The Q-PCR assay was performed using total RNA harvested from U373MG cells. b The interaction of ZNF179 and PLZF was revealed using immunoprecipitation analysis of an EGFP-PLZF plasmid transiently transfected together with HA or HAZNF179 plasmids. c The interaction of ZNF179 with PLZF can downregulate $I G F B P 3$ and $B I K$ promoter activity. A representation of reporter constructs are shown (upper panel). Using cell lysates, the reporter assay was conducted by examining the luciferase activity of a co-transfected $I G F B P 3$ reporter or $B I K$ reporter/ZNF179 expression vector/PLZF expression vector. d ZNF179 reduces $I G F B P 3$ reporter or $B I K$ reporter activities after IL- $1 \beta$ treatment in U373MG cells. Lentiviral vectors were used to express shLacZ and shZNF179. After a 2-day infection, these constructs were co-transfected with expression and promoter vectors. A reporter assay was conducted using the luciferase activity within cell lysates. e The interaction of ZNF179 with PLZF can directly binds to the $I G F B P 3$ and $B I K$ promoter in vivo. A chromatin immunoprecipitation assay was performed with the immunoprecipitation products at the indicated Abs from U373MG cells treated with IL$1 \beta$. $\left({ }^{*} p<0.05, * * p<0.01, * * * p<0.001\right.$, Student's $t$ test $)$. shZN short hairpin ZNF179; FL full length; PI promoter I; PII promoter II; shLacZ $\operatorname{sh} \beta$-galactosidase

the first evidence to support ZNF179's antiapoptotic role, particularly in astrocytes within a damaged or inflammatory environment.

CEBPD is induced in age-associated disorders, such as $\mathrm{AD}$, atherosclerosis [28], type 2 diabetes [29], and rheumatoid arthritis $[9,30]$. These discoveries imply that CEBPD may play a central role in inflammation-related diseases. Our previous $[8,11]$ and current studies indicate that the inactivation of CEBPD in astrocytes could improve the survival of neuron in inflammatory diseases. Small chemical drugs $(<400 \mathrm{Da})$ may cross the blood-brain barrier via lipid-mediate-free diffusion [31]. Carnosic acid can penetrate the blood-brain barrier and could be a useful drug for $\mathrm{A} \beta$-induced neurodegeneration as $\mathrm{AD}$ [32]. We previously demonstrated that rosmanol (molecular weight $346.41 \mathrm{Da}$ ), a natural carnosic acid, derived from the herb rosemary and inotilone (molecular weight 218.21 Da), an unusual 5-methyl-3(2H)-furanone derivative, can inhibit CEBPD activation in macrophages [9]. Therefore, rosmanol and inotilone can be tested toward the prevention or treatment of $\mathrm{AD}$ in the future.

Znf179 is specifically expressed in the brain and can contribute to neuronal differentiation and survival [12]. Unlike neurons, the increase of ZNF179 in astrocytes was responsive to inflammatory cytokines (Figs. 2, 3, and S1C). Here, we found that the transcription of $Z N F 179$ gene is responsive to IL- $1 \beta$ through the action of enhanced binding and transactivation activity of CEBPD on its promoter region in astrocytes. Importantly, the antiapoptotic role of ZNF179 in astrocytes may explain why active astrocytes are resistant to cell death in an inflammatory environment. Interestingly, the GSK3 $\beta$ inhibitor, $\mathrm{LiCl}$, enhanced neuron survival but caused growth retardation in astrocytes [33]. A study showed that CEBPD is a GSK3 $\beta$ substrate, and CEBPD phosphorylation contributes to the transcriptional regulation of CEBPDmediated downstream target genes. Therefore, the relevance of GSK $3 \beta$-mediated phosphorylation of CEBPD in ZNF179 transcriptional activation in astrocytes requires further investigation.

PLZF has been suggested to be a transcriptional repressor and antiapoptotic for neurons in stroke [34]. PLZF interacts with SMRT/N-CoR-mSin3A-HDAC-repressing complexes to suppress gene transcription [35, 36]. Several lines of evidence suggest that PLZF has antiapoptotic effects. For example, PLZF can inhibit caspase 3 and caspase 7 activity in neurons [34]; however, the specific mechanism remains unknown. In this study, we further found that ZNF179 expression was activated and interacted with PLZF upon IL- $1 \beta$ treatment to promote antiapoptosis in astrocytes. IGFBP3 is a common pro-apoptosis gene, and it has been shown to enhance and attenuate the actions of IGF-I [37]. IGF-I is mediated by the IGF-I receptor and interacts with IGFBP3 to inhibit cell growth and induce apoptosis [24]. Previous studies showed that IGFBP3 activates the apoptotic pathway through Bcl2 family [38]. Increased PLZF attenuated IGFBP 3 transcription. A constitutive binding of PLZF and increased binding of ZNF179 on the IGFBP3 promoter were observed after IL$1 \beta$ treatment. However, the nuclear-cytoplasmic shuttle of ZNF179 did not change in response to IL-1 $\beta$ stimulation (Fig. S4). This observation implies that cytosolic and nuclear ZNF179 may play distinct roles in IL-1 $\beta$-treated astrocytes. These data also suggest that IL-1 $\beta$ can induce nuclear ZNF179 binding to the preexisting PLZF on IGFBP3 and $B I K$ promoter to suppress its transcription. Although the transcription of the proapoptotic GADD $45 B$ and $R Y B P$ genes is repressed by the overexpression of ZNF179, our preliminary results show that exposure to IL- $1 \beta$ has no effect on $G A D D 45 B$ and $R Y B P$ transcription. These data suggest that ZNF179 can interact with other IL-1 $\beta$-independent transcription repressors or complexes to repress gene transcription; however, this hypothesis needs to be further investigated

Acknowledgments This work was supported by grant NHRI-EX10210143 NI from the National Health Research Institutes, grant NSC1002320-B-006-020 from the National Science Council, Ministry of Health and Welfare (MOHW103-TD-B-111-05), and the Headquarters of University Advancement at the National Cheng Kung University from the Ministry of Education.

Conflict of interest None of the authors has a conflict of interest to declare in relation to the present research.

Open Access This article is distributed under the terms of the Creative Commons Attribution License which permits any use, distribution, and reproduction in any medium, provided the original author(s) and the source are credited. 


\section{References}

1. Franceschi C (2007) Inflammaging as a major characteristic of old people: can it be prevented or cured? Nutr Rev 65(12):S173-S176

2. Cerbai F, Lana D, Nosi D, Petkova-Kirova P, Zecchi S, Brothers HM, Wenk GL, Giovannini MG (2012) The neuron-astrocyte-microglia triad in normal brain ageing and in a model of neuroinflammation in the rat hippocampus. PLoS One 7(9):e45250

3. Garwood CJ, Pooler AM, Atherton J, Hanger DP, Noble W (2011) Astrocytes are important mediators of Abeta-induced neurotoxicity and tau phosphorylation in primary culture. Cell Death Dis 2:e167

4. Song JH, Bellail A, Tse MC, Yong VW, Hao C (2006) Human astrocytes are resistant to Fas ligand and tumor necrosis factorrelated apoptosis-inducing ligand-induced apoptosis. J Neurosci 26(12):3299-3308

5. Salminen A, Ojala J, Kaarniranta K, Haapasalo A, Hiltunen M, Soininen H (2011) Astrocytes in the aging brain express characteristics of senescence-associated secretory phenotype. Eur J Neurosci 34(1):3-11

6. Herrmann JE, Imura T, Song BB, Qi JW, Ao Y, Nguyen TK, Korsak RA, Takeda K, Akira S, Sofroniew MV (2008) STAT3 is a critical regulator of astrogliosis and scar formation after spinal cord injury. $\mathrm{J}$ Neurosci 28(28):7231-7243

7. Li R, Strohmeyer R, Liang Z, Lue LF, Rogers J (2004) CCAAT/ enhancer binding protein delta (C/EBPdelta) expression and elevation in Alzheimer's disease. Neurobiol Aging 25(8):991-999

8. Ko CY, Chang LH, Lee YC, Sterneck E, Cheng CP, Chen SH, Huang AM, Tseng JT, Wang JM (2012) CCAAT/enhancer binding protein delta (CEBPD) elevating PTX3 expression inhibits macrophagemediated phagocytosis of dying neuron cells. Neurobiol Aging 33(2):422 e411-425

9. Chang LH, Huang HS, Wu PT, Jou IM, Pan MH, Chang WC, Wang DD, Wang JM (2012) Role of macrophage CCAAT/enhancer binding protein delta in the pathogenesis of rheumatoid arthritis in collagen-induced arthritic mice. PLoS One 7(9):e45378

10. Cardinaux JR, Allaman I, Magistretti PJ (2000) Pro-inflammatory cytokines induce the transcription factors $\mathrm{C} / \mathrm{EBPbeta}$ and C/EBPdelta in astrocytes. Glia 29(1):91-97

11. Ko CY, Wang WL, Wang SM, Chu YY, Chang WC, Wang JM (2014) Glycogen synthase kinase-3beta-mediated CCAAT/enhancer-binding protein delta phosphorylation in astrocytes promot es migration and activation of microglia/macrophages. Neurobiol Aging 35(1):24-34

12. Pao PC, Huang NK, Liu YW, Yeh SH, Lin ST, Hsieh CP, Huang AM, Huang HS, Tseng JT, Chang WC, Lee YC (2011) A novel RING finger protein, Znf179, modulates cell cycle exit and neuronal differentiation of P19 embryonal carcinoma cells. Cell Death Differ 18(11):1791-1804

13. Seki N, Hattori A, Muramatsu M, Saito T (1999) cDNA cloning of a human brain finger protein, BFP/ZNF179, a member of the RING finger protein family. DNA Res Int J Rapid Publ Rep Genes Genomes 6(5):353-356

14. Orimo A, Inoue S, Ikeda K, Sato M, Kato A, Tominaga N, Suzuki M, Noda T, Watanabe M, Muramatsu M (1998) Molecular cloning, localization, and developmental expression of mouse brain finger protein (Bfp)/ZNF179: distribution of bfp mRNA partially coincides with the affected areas of Smith-Magenis syndrome. Genomics 54(1):59-69

15. Sterneck E, Paylor R, Jackson-Lewis V, Libbey M, Przedborski S, Tessarollo L, Crawley JN, Johnson PF (1998) Selectively enhanced contextual fear conditioning in mice lacking the transcriptional regulator CCAAT/enhancer binding protein delta. Proc Natl Acad Sci U S A 95(18):10908-10913

16. Allan SM, Rothwell NJ (2003) Inflammation in central nervous system injury. Philos Trans R Soc Lond Ser B Biol Sci 358(1438): 1669-1677
17. Saijo K, Winner B, Carson CT, Collier JG, Boyer L, Rosenfeld MG, Gage FH, Glass CK (2009) A Nurr1/CoREST pathway in microglia and astrocytes protects dopaminergic neurons from inflammationinduced death. Cell 137(1):47-59

18. Franke H, Sauer C, Rudolph C, Krugel U, Hengstler JG, Illes P (2009) P2 receptor-mediated stimulation of the PI3-K/Akt-pathway in vivo. Glia 57(10):1031-1045

19. Kimura T, Arakawa Y, Inoue S, Fukushima Y, Kondo I, Koyama K, Hosoi T, Orimo A, Muramatsu M, Nakamura Y, Abe T, Inazawa J (1997) The brain finger protein gene (ZNF179), a member of the RING finger family, maps within the SmithMagenis syndrome region at 17p11.2. Am J Med Genet 69(3): 320-324

20. Stanton SE, Blanck JK, Locker J, Schreiber-Agus N (2007) Rybp interacts with Hippi and enhances Hippi-mediated apoptosis. Apoptosis Int J Program Cell Death 12(12):2197-2206

21. Chinnadurai G, Vijayalingam S, Rashmi R (2008) BIK, the founding member of the BH3-only family proteins: mechanisms of cell death and role in cancer and pathogenic processes. Oncogene 27(Suppl 1): S20-S29

22. Ou DL, Shen YC, Yu SL, Chen KF, Yeh PY, Fan HH, Feng WC, Wang CT, Lin LI, Hsu C, Cheng AL (2010) Induction of DNA damage-inducible gene GADD45beta contributes to sorafenibinduced apoptosis in hepatocellular carcinoma cells. Cancer Res 70(22):9309-9318

23. Williams AC, Smartt H, AM HZ, Macfarlane M, Paraskeva C, Collard TJ (2007) Insulin-like growth factor binding protein 3 (IGFBP-3) potentiates TRAIL-induced apoptosis of human colorectal carcinoma cells through inhibition of NF-kappaB. Cell Death Differ 14(1):137-145

24. Kielczewski JL, Hu P, Shaw LC, Li Calzi S, Mames RN, Gardiner TA, McFarland E, Chan-Ling T, Grant MB (2011) Novel protective properties of IGFBP-3 result in enhanced pericyte ensheathment, reduced microglial activation, increased microglial apoptosis, and neuronal protection after ischemic retinal injury. Am J Pathol 178(4):1517-1528

25. Lin DY, Huang CC, Hsieh YT, Lin HC, Pao PC, Tsou JH, Lai CY, Hung LY, Wang JM, Chang WC, Lee YC (2013) Analysis of the interaction between zinc finger protein 179 (Znf1 79) and promyelocytic leukemia zinc finger (Plzf). J Biomed Sci 20:98-107

26. Hsiao HY, Chen YC, Chen HM, Tu PH, Chern Y (2013) A critical role of astrocyte-mediated nuclear factor-kappaBdependent inflammation in Huntington's disease. Hum Mol Genet 22(9):1826-1842

27. Swanson RA, Ying W, Kauppinen TM (2004) Astrocyte influences on ischemic neuronal death. Curr Mol Med 4(2):193-205

28. Takata Y, Kitami Y, Yang ZH, Nakamura M, Okura T, Hiwada K (2002) Vascular inflammation is negatively autoregulated by interaction between CCAAT/enhancer-binding protein-delta and peroxisome proliferator-activated receptor-gamma. Circ Res 91(5):427433

29. Gao H, Bryzgalova G, Hedman E, Khan A, Efendic S, Gustafsson JA, Dahlman-Wright K (2006) Long-term administration of estradiol decreases expression of hepatic lipogenic genes and improves insulin sensitivity in ob/ob mice: a possible mechanism is through direct regulation of signal transducer and activator of transcription 3. Mol Endocrinol 20(6):1287-1299

30. Nishioka K, Ohshima S, Umeshita-Sasai M, Yamaguchi N, Mima T, Nomura S, Murata N, Shimizu M, Miyake T, Yoshizaki K, Suemura M, Kishimoto T, Saeki Y (2000) Enhanced expression and DNA binding activity of two CCAAT/enhancer-binding protein isoforms, $\mathrm{C} /$ EBPbeta and C/EBPdelta, in rheumatoid synovium. Arthritis Rheum 43(7):1591-1596

31. Pardridge WM (2012) Drug transport across the blood-brain barrier. J Cerebr Blood F Met 32(11):1959-1972 
32. Azad N, Rasoolijazi H, Joghataie MT, Soleimani S (2011) Neuroprotective effects of carnosic acid in an experimental model of Alzheimer's disease in rats. Cell J 13(1):39-44

33. Gilad GM, Gilad VH (2007) Astroglia growth retardation and increased microglia proliferation by lithium and ornithine decarboxylase inhibitor in rat cerebellar cultures: cytotoxicity by combined lithium and polyamine inhibition. J Neurosci Res 85(3): 594-601

34. Seidel K, Kirsch S, Lucht K, Zaade D, Reinemund J, Schmitz J, Klare S, Li Y, Schefe JH, Schmerbach K, Goldin-Lang P, Zollmann FS, Thone-Reineke C, Unger T, Funke-Kaiser H (2011) The promyelocytic leukemia zinc finger (PLZF) protein exerts neuroprotective effects in neuronal cells and is dysregulated in experimental stroke. Brain Pathol 21(1):31-43
35. Parrado A, Robledo M, Moya-Quiles MR, Marin LA, Chomienne C, Padua RA, Alvarez-Lopez MR (2004) The promyelocytic leukemia zinc finger protein down-regulates apoptosis and expression of the proapoptotic BID protein in lymphocytes. Proc Natl Acad Sci U S A 101(7):1898-1903

36. Girard N, Tremblay M, Humbert M, Grondin B, Haman A, Labrecque J, Chen B, Chen Z, Chen SJ, Hoang T (2013) RARalpha-PLZF oncogene inhibits C/EBP alpha function in myeloid cells. Proc Natl Acad Sci U S A 110(33):13522-13527

37. Brosseau C, Pirianov G, Colston KW (2013) Role of insulin-like growth factor binding protein-3 in 1,25-dihydroxyvitamin-d3-induced breast cancer cell apoptosis. Int J Cell Biol 2013 ArticleID:960378

38. Firth SM, Baxter RC (2002) Cellular actions of the insulin-like growth factor binding proteins. Endocr Rev 23(6):824-854 